\title{
BIOÉTICA HERMENÉUTICA
}

\author{
Raúl Villarroel \\ Facultad de Filosofía y Humanidades \\ Universidad de Chile
}

Correspondencia: Prof. Raúl Villarroel. Ignacio Carrera Pinto 1025, Ñuñoa. E-mail: rvillarr@uchile.cl 



\section{BIOÉTICA HERMENÉUTICA}

Raúl Villarroel

\section{Resumen}

Intentando sortear las dificultades que en la reflexión filosófica se plantean a la revitalización de un proyecto que busque hacer converger la ostensible diversidad de criterios morales característica de la época actual, se aborda una particular comprensión de la bioética a partir de claves hermenéuticas. De este modo se pretende exceder legítimamente el conjunto de dificultades ocasionadas por la tensión y la discontinuidad que se ha producido entre el desarrollo cognoscitivo y el desarrollo moral de la humanidad en dos ámbitos significativos: el de la salud y el del medio ambiente. Para ello se busca transitar desde el sistema acabado y definitivo del reduccionismo cientificista al borde diferencial interpretativo, donde ambas dimensiones enunciadas son atestiguadas, más bien, desde una condición intrínsecamente problemática, conjetural e imprevisible, siempre reticente a cualquier encapsulamiento univocista.

PALABRAS CLAVE: Bioética, Hermenéutica, Interpretación, Eticismo, Salud, Medio ambiente, Texto, Ética, Tecnociencia.

\section{Resumo}

Tentando apreender as dificuldades que a reflexão filosófica apresenta à revitalização de um projeto que busque compatibilizar as expressivas diversidades de critérios morais característicos de nossa época, apresenta-se uma nova compreensão da bioética à partir de instrumentos da hermenêutica. Desse modo pretende-se ultrapassar as dificuldades geradas pela tensão e descontinuidade que foram produzidas pelo desenvolvimento cognoscitivo e moral da humanidade nos âmbitos da saúde e do meio ambiente. Para tanto busca-se transitar desde os limites do sistema acabado do reducionismo científico até as fronteiras da interpretação diferencial, onde ambas as dimensões são avaliadas através de uma condição intrinsicamente problematizada, conjectural e imprevisível, sempre questionando qualquer tipo de limitação interpretativa. 


\begin{abstract}
Trying to overcome difficulties posed by philosophical reflection to the revitalization of a project for achieving convergence among the diversity of moral criteria typical of our epoch- a peculiar understanding of Bioethics, based on hermeneutical clues, is proposed. By so doing, we pretend to surpass in a legitimate way the totality of difficulties caused by the tension and discontinuity between cognitive and moral developments in two significant areas: health and environment. For achieving this aim we propose to pass along from the complete and definitive system of scientificistic reduccionism to the differencial interpretative border, where both dimensions are visualized rather from an intrinsically problematic condition, conjectural and unforeseeable, permanently reticent to whatever interpretative restriction.
\end{abstract}

KEY-WORDS: Bioethics; Hermeneutics; Interpretation; Ethicism; Health; Environment; Text; Ethics; Technoscience.

\section{Résumé}

Dans le texte que suit nous tâchons d'aborder la bioéthique dans une particulière compréhension grâce à des clés herméneutiques; tout en essayant d'esquiver les difficultés que posse, dans le cadre d'une réflexion philosophique, la mise au jour d'un projet qui doit permettre la convergence des diversités de jugements moraux, caractéristique de notre temps. En agissant ainsi on prétend dépasser de façon légitime les difficulttés provoquées par la tension et la discontinuité qui s'est produit entre le devélopement cognitif et le devélopement moral de l'humanité dans deux sujets significatifs: celui de la santé et celui de l'environnement. Pour y arriver on tente de passer du système achevé et définitif du reductionnisme scientifique au domaine de l'interprétation où les deux dimensions ennoncées sont explicitées dans leur condition intrinsèquement problématique, conjecturale et imprevisible, toujours réticent à n'importe quel enfermenent univoque.

MOTS CLÉS: Éthique; Bioétique; Hermenéutique; Interprétation; Éthicisme; Santé; Environnement; Texte; Technoscience. 


\section{Introducción}

"Si en otros tiempos la medicina monopolizó las ciencias de la vida, hoy no es así, y por tanto sería un error reducir el ámbito de la bioética al de la ética médica, o convertirla en mera deontología profesional.

Se trata, a mi parecer, de mucho más, de la ética civil propia de las sociedades occidentales en estas tortuosas postrimerías del segundo milenio."

"Fundamentos de Bioética". Diego Gracia.

La idea central del texto que a continuación se presenta tiene que ver con una reflexión que intenta explicar y comprender $f i$ losóficamente el discurso bioético. Busca con ello proyectar la posición que más propiamente le correspondería ocupar en el contexto de una sociedad secularizada como la presente; así llamada "moderna" y organizada en torno al predominio de una cosmovisión tecnocientífica característica y definitoria de su identidad. Aunque acá será reconocida en función de los parámetros teóricos que enuncian y describen su crisis fundamental, la del quiebre de las estructuras matrices que le dieron sustento filosófico y la de la deslegitimación creciente del conjunto de prácticas heterogéneas que la han venido caracterizando desde hace siglos.

En virtud de lo anterior, esta reflexión se sitúa en la dimensión de los problemas referidos a la fundamentación bioética, según la modalidad que se ha hecho habitual hasta nuestros días para clasificar sus ámbitos de pertinencia. Lo que se pretende abordar son los conceptos y perspectivas filosóficas que puedan intervenir a modo de referencias decisivas para la expectativa de legitimidad que tiene la reflexión bioética actual. Sobre todo respecto de aquellas referencias teóricas que convergen en la meditación acerca de nuestro tiempo, como un tiempo signado por el desarrollo de un proyecto que ha mostrado en nues- tros días - conjuntamente con sus logros innegables - sus extremos y sus excesos.

Desde aquí ya se puede asumir que la bioética se localiza en la encrucijada contemporánea donde convergen y se problematizan dificultades de índole moral derivadas de la intervención técnica sobre la vida (en sus múltiples expresiones) y el medio ambiente que de manera global la sustenta. Como se sabe, hoy en día es posible constatar una profunda crisis planetaria de dimensiones políticas, económicas y espirituales, que afecta en su totalidad a la vida de las personas. De hecho, la salud, el entorno, nuestra relación con los semejantes, son asuntos sobre los que la crisis repercute de manera más incisiva, al punto de convertirse en la peor amenaza que la humanidad haya debido enfrentar. Incluso, ni siquiera considerando el inminente peligro de un desastre nuclear, el solo riesgo de catástrofe para el ecosistema global y la subsecuente evolución de la vida en el planeta es en sí un fenómeno aterrador.

Pensando en estos hechos $-\mathrm{y}$ en su filiación teórica interdisciplinaria- se piensa que la bioética puede, por una parte, realizar un aporte decisivo en cuanto a la necesidad de hacer surgir un nuevo modo de aproximación a los problemas fundamentales de nuestro tiempo, y contribuir, por otra, tanto en la búsqueda de criterios de solución para ellos como en la preparación de un nuevo arraigo para lo humano en los tiempos venideros. Se trata así de proponer delimitaciones conceptuales desde las cuales la bioética pueda configurarse como una perspectiva de articulación coherente y sistemática entre la comprensión técnica del mundo contemporáneo y la particular comprensión ética que puede hacerse presente tras la constatación de la crisis disolutiva de los referentes filosóficos fundamentales de la modernidad.

Esta reflexión intenta proponer una orientación de tipo hermenéutico para el análisis de los problemas y discursos particulares que convergen en ella, y concebir a la interpreta- 
ción como la operación de sentido que puede dar más propiamente cuenta en el presente de los complejos problemas relativos a la experiencia humana en el contexto de la sociedad actual. De esta manera, se intenta adherir a aquella definición de la bioética que la muestra como un principio regulador y guía para la deliberación y la acción en nuestro tiempo, concibiéndola como una perspectiva carente de pretensiones de hegemonía fundamentalista en el plano moral, al tiempo que abierta a un diálogo interepistémico amplio, capaz de diseñar y orientar, tanto la investigación como el conjunto de prácticas tecnocientíficas a la luz del consenso plural de todos los actores y discursos involucrados.

Así se quiere pensar, entonces, que la bioética puede llegar a constituirse en una apertura auspiciosa para el próximo siglo en el plano de la explicación y la comprensión de los problemas fundamentales que aquejan a la humanidad finisecular, en la medida que, por su propia e inédita modalidad de aproximación a los hechos, representa un punto de flexión hasta ahora desconocido en el pensamiento. Una posibilidad de esta naturaleza sólo puede resultar factible a partir del reconocimiento del conjunto de transformaciones a que ha dado lugar la, así llamada, "disposición técnica del mundo" en todos los ámbitos de la experiencia. Ello implica, necesariamente, llevar a cabo un intento de ampliar el alcance de las preocupaciones bioéticas más allá de las estrictas fronteras de las ciencias biomédicas, en lo referente al ámbito sanitario en general y a la relación médico-paciente en particular - las que, aun ocupando un lugar de importancia en la problemática, no agotan el espectro de hechos conflictivos que pueden ser abordados con identidad de método y propósito-, hasta dar cuenta de otras esferas problemáticas en que se hacen manifiestas dificultades semejantes, como son, por ejemplo, las relaciones entre la especie humana y el resto de las especies naturales, o las problemáticas pretensiones de articulación de una con- ciencia ética referida a los problemas medioambientales, demográficos, etc.; considerando, además, que este tipo de problemas constituyen sólo la parte visible de una dificultad más profunda relativa a las maneras de vivir y de ser-en-sociedad en este planeta. En efecto, en tal sentido se entenderá que la bioética puede contribuir decisivamente en la búsqueda de respuestas generales y/ o específicas para un amplio haz de situaciones conflictivas ocasionadas por el propio despliegue técnico —en relación con muchos aspectos inmediatos, concretos o contingentes que las actuales coordenadas sociales, políticas y económicas del mundo establecen—, si es capaz de promover en todos los ámbitos posibles de la interacción humana - particularmente en aquellos en que se concentran decisiones fundamentales - una especial sensibilidad moral que haga posible la contención de sus efectos y consecuencias devastadoras. Esto, naturalmente, precisará del desarrollo de una manera de abordar los problemas que, no estando transida por el mero cálculo técnico, prescinda de ciertas posiciones dominantes de la subjetividad que han caracterizado al pensamiento moderno.

En esta perspectiva, la interpretación como se ha señalado- emerge entendida en cuanto evento de naturaleza dialógica, que permite a los diversos interlocutores ponerse en juego en condiciones de igualdad y comprenderse en la medida en que son comprendidos en un horizonte ontológico no metafísico, del que en verdad no "disponen", sino que, más bien, los dispone a ellos como tales. Por eso se propondrá que la posibilidad de articulación coherente de un pensamiento bioético pueda ser remitida a una dimensión de orden retórico, de ajuste de las diversidades, de reconstrucción de la discontinuidad y la dispersión entre los diferentes actores, como reunión de una multiplicidad de discursos (científicos, filosóficos, políticos, económicos, religiosos, etc.) y que todas estas formas simbólicas puedan consi- 
derarse como lugares pertinentes para una posible experiencia moral.

En lo sucesivo, se tendrá en cuenta la presencia persistente y constatable de la hermenéutica en la cultura actual, la que, inspirada originalmente en filósofos como Schleiermacher y Dilthey, se desarrolla hoy en diversas direcciones, abarcando o influyendo en sentido amplio a muchas posiciones filosóficas, hasta llegar a constituir por lo tanto un marco de fundamentación filosófica amplio que se considera, en este caso, pertinente para la definición de bioética que acá se propone. No obstante, se comprende que su patente actualidad entraña también riesgos teóricos de importancia y plantea problemas y exigencias al pensamiento actual —y también a esta reflexiónque son relativos, por una parte, a evitar que una bioética inspirada en estas propuestas se convierta en una simple apología de la multiplicidad irreductible de los universos culturales que se abren en nuestra época y, por otra, a evitar que pueda llegar a recaer en una suerte de nueva proposición metafísica de reconfiguración de viejos esquemas; es decir, en una simple ideología de recambio, en un proyecto moral meramente cosmético, coincidente con una suerte de lugar común de la moralidad en nuestro tiempo.

El horizonte teórico en el que esta reflexión busca situarse resulta estar orientado éticamente por cuanto reivindica el alcance de legitimidad de ámbitos que son irreductibles a la competencia del método científico-positivo, y se dirige preferentemente hacia un intento de esclarecimiento de lo que se podría entender como una recomposición de la subjetividad tanto individual como colectiva acontecida en el marco de un entrecruzamiento de prácticas innovadoras referidas al modus vivendi del presente. $\mathrm{Y}$ en ese sentido, se configura como una instancia que asume los aspectos centrales de la tradición crítica de una metafísica que se representa en nuestro tiempo por el cientificismo y la categoría particular de lo que se ha dado en llamar el "saber-poder".
Asimismo, se puede reconocer que el pensamiento hermenéutico contribuye de manera importante en esa suerte de revitalización de la moral ("rehabilitación de la filosofía práctica", tal vez) que aparece como una de las características más sobresalientes de las últimas décadas en el mundo y que le aporta al encuadre bioético una condición propicia para su desarrollo, en cuanto se llega a entender que puede representar un recurso valiosísimo para encontrar un fundamento distinto de la fuerza a la resolución de las controversias y el disenso. Habría que convenir en este sentido que quien quiera resolver confrontaciones morales sin recurrir a dispositivos estratégicos o coactivos, con autoridad de base, tendrá que admitir el acuerdo entre las partes, la legitimidad del otro o la validez de todo interlocutor, y, en definitiva, el abandono de toda pretensión de hegemonía con respecto a la categoría de la verdad o de una concepción concreta y particular acerca de la vida buena, como los medios exclusivos para alcanzar la resolución de las disputas entre "extraños morales". De tal manera, un reconocimiento del carácter irrebasable o insuperable de la argumentación parece ser difícil de evitar, al menos si lo que se pretende es avanzar responsablemente hacia una condición diversa de vida para el hombre.

En este sentido, una nueva comprensión del conjunto de problemas asociados a la salud y al medio ambiente deberá basarse en la comprensión de las relaciones y dependencias recíprocas y esenciales de todos los fenómenos. Una visión semejante - como la que la bioética puede llegar a encarnar hoy en día - trasciende los límites disciplinarios y las rígidas categorías conceptuales de los saberes establecidos. Actualmente no hay, al parecer, estructura conceptual o institucional alguna que esté firmemente arraigada como para penetrar con profundidad las nuevas condiciones paradigmáticas de la realidad. Una disposición muy diferente a la conocida está emergiendo en medio de estos tiempos turbulentos y buscando gradualmen- 
te alcanzar diferentes modos de pensar y organizar los hechos de la existencia. Aunque no sea posible determinar para ninguna de ellos una condición de privilegio o supremacía en cuanto a sus diversas aproximaciones al tejido polinivelado y recíprocamente relacionado de la realidad. ${ }^{i}$

Es claro que la problemática general de la salud, por ejemplo, en la era de la ciencia y de la técnica, reviste un extraordinario interés en este sentido (otro tanto ocurre con los fenómenos medioambientales), porque no existe otro terreno en el cual los progresos de la investigación moderna avancen tanto hacia el campo de tensiones de las políticas sociales como en éste; los dominios de la ciencia siempre se proyectan sobre la vida cotidiana y cuando de lo que se trata es de la aplicación del conocimiento científico a nuestra salud y a todos los aspectos vinculados con ella debemos necesariamente convenir en que tales circunstancias problemáticas pueden ser abordadas desde muy diversos puntos de vista y enfoques considerando su comprensión integral, y no exclusiva o excluyentemente desde la perspectiva científico-positiva — sustentada en el paradigma cartesiano del conocimiento-, que es la que parece ser, de modo habitual, más decisiva.

En cuanto a esto mismo, dado que, evidentemente, la salud tiene varias dimensio-

\footnotetext{
Incluso en el propio corazón de la ciencia contemporánea, el denominado enfoque "bootstrap" de la física, propuesto a comienzos de la década de los 60 por Geoffrey Chew, marca una orientación a la misma necesidad de rebajar la validez de ciertos conceptos privilegiados que tradicionalmente han mantenido un dominio de la experiencia científica. Según se conoce, la física siempre buscó encontrar los constituyentes últimos de la materia. El principio filosófico del bootstrap rechaza la concepción física tradicional de los bloques de materia fundamentales y tampoco acepta ningún tipo de entidades básicas; es decir, no acepta constantes o ecuaciones fundamentales. Concibe al universo como una red dinámica de fenómenos relacionados entre sí y cree que la naturaleza debe concebirse, en estos términos, sólo en virtud de su autoconsistencia.
}

nes y todas ellas no surgen sino de una complejísima interacción de los múltiples aspectos físicos, psicológicos y sociales de la naturaleza humana, podemos llegar a convenir en que la concentración habitual de la práctica sanitaria desarrollada hasta la fecha sobre fragmentos cada vez más diminutos del organismo tiende inevitablemente a perder de vista la humanidad integral del paciente, con lo que la salud queda de inmediato reducida a una mera función mecánica. El modelo biomédico reduccionista, todavía predominante en la comprensión del hecho de la salud, por su profunda inspiración cartesiana $^{\text {ii }}$, ha conminado a los médicos a centrarse en esta supuesta "máquina" del cuerpo y a olvidar los aspectos psicológicos y socioambientales de la enfermedad. De aquí se desprende la necesidad de reformular — mejor si es hermenéuticamente- un pensamiento que contribuya a desvincular la tarea médica del perfil manipulador que le confiere su exclusiva reducción a práctica mecánica correctora de disfunciones orgánicas específicas. Se necesita, de hecho, una concepción de salud mucho más extensa, que incluya sus ámbitos individuales, sociales y ecológicos; que tenga una visión integral de los seres vivientes y, por ende, una visión integral de éstos con su entorno.

El "cientificismo" médico ha sumido en el olvido, prácticamente, al "arte de curar", que es un aspecto esencial de la medicina, porque contribuye a desencadenar la respuesta coordinada del organismo a las tensiones ambientales que lo influyen. Esta manera de comprender el fenómeno de la curación involucra toda una conceptualización que escapa a la posibi-

ii Durante el desarrollo histórico de la ciencia en Occidente se puede constatar un marcado paralelismo entre la biología y la medicina. Por ello, resulta completamente comprensible que una visión mecanicista de la vida, originalmente surgida en el campo de la biología, haya dado fisonomía a la actitud médica ante la salud y la enfermedad. El paradigma cartesiano que influyó al pensamiento médico dio, finalmente, con el así denominado "modelo biomédico". 
lidad de formulación exacta requerida por la estructura de las ciencias médicas contemporáneas. En ella concurren poderosamente criterios diversos, holísticos más bien, que abarcan al cuerpo y la mente del paciente, a su propia autoimagen tanto como a su dependencia del entorno físico y social; su relación con el cosmos, con sus divinidades; en fin, criterios nunca limitados de manera exclusiva a los fenómenos físico-químicos como en el caso de la concepción biomédica.

Ahora, por último, considerando una convicción de marcada presencia en el pensamiento contemporáneo, según la cual los problemas bioéticos se plantean en los actuales escenarios definidos por la fragmentación moral acontecida como consecuencia de la disolución progresiva de la fe y de todos los cambios significativos que han tenido lugar en el espacio de las convicciones éticas y ontológicas de Occidente, se aspira a la posibilidad de que la bioética, concebida desde una apertura comprensiva de orientación hermenéutica, implique como único imperativo el ejercicio de la interpretación (en este caso en el sentido de una "traducción"), para conducir los discursos particulares o específicos, las diversas esferas del interés y los ámbitos de racionalidad autónomos y escindidos entre sí - los de la ética y la medicina, los de la ética y la política, los de la ética y la economía, por ejemplo-, a una relocalización en el contexto de una base común de valores que puedan ser efectivamente compartidos por una comunidad histórica viviente que se expresa mediante su lengua y que reconoce en ésta un horizonte de referencia, como ideal regulativo de una comunidad de vida que está siempre en proyecto, en vías de realización.

"Queda claro que existen dos medidas: la una, en manos de la ciencia;

la otra, en el todo de nuestro estar-en el mundo".

Hans-Georg Gadamer. El estado oculto de la salud.
En la actualidad suele pensarse que el desencanto o el marcado escepticismo que impide unificar criterios morales obedece a la tensión y discontinuidad que se ha venido generando entre el desarrollo cognoscitivo y el desarrollo moral de la humanidad. Esta tensión representa un desafío para el pensamiento actual pues induce a considerar que a estas alturas lo que está en juego es la definición y la preparación de un nuevo arraigo para lo humano, que pueda ofrecer contrapeso a las dificultades derivadas del habitar técnico moderno.

Ahora bien, existen por lo menos dos grandes dificultades para acometer filosóficamente semejante tarea. Primero, porque el pensar filosófico actualmente ya no puede cumplir con su antigua aspiración de ser el instrumento apropiado de intervención o transformación de la realidad. Y, en segundo término, por la dificultad que existe para validar un fundamento que sea capaz de sobreponerse a la impronta de la crítica al humanismo y a la ética desplegada por una cierta corriente de la reflexión contemporánea.

A pesar de ello, igualmente, hoy en día se levantan propuestas que lo intentan y que podrían ser consideradas como la expresión de una suerte de revitalización del pensamiento ético en el mundo. Parece evidente que un interés de este tipo gana espacios con mucha rapidez en una multiplicidad de ámbitos de la acción humana. Al parecer, una nueva utopía de la moral se estaría instituyendo; en tanto el refuerzo del ideal de la responsabilidad, que es el rasgo más visible de esta circunstancia, obedece o coincide con el venir a menos de una particular representación determinista del progreso y la felicidad, que no es sino aquella prometida por la ciencia y la técnica.

En consecuencia, si resulta ser de interés para nosotros el visualizar a la bioética como una de aquellas expresiones concretas del renacer ético de nuestros días, con una supuesta plena capacidad de hacerse cargo de las de- 
licadas cuestiones que surgen como producto de la eclosión tecnológica en curso, habrá que reconocer que, primeramente, dicho resurgimiento de la ética en la actualidad se identifica con una cierta peculiaridad de carácter, que, en verdad, lo hace muy diferente de todo lo conocido al respecto y, en segundo lugar, que es necesario explicitar los aspectos centrales de dicha particularidad para comprender las delimitaciones específicas dentro de las cuales la bioética tendría sentido y, a la vez, posibilidad de validarse como una suerte de paradigma de comprensión de la realidad actual, según lo ha señalado Gilbert Hottois (1). En este caso, lo que debe ser necesariamente reconocido antes que todo es el hecho puntual de que la apariencia moral de la sociedad contemporánea transita de forma contradictoria entre dos extremos muy diferentes: por un lado, hacia esta reactivación innegable de la moral que avanza sobre una multiplicidad de dominios de la vida humana y, por otro, hacia la creciente descomposición social que gangrena el orden establecido y para la cual huelgan mayores descripciones en este momento.

¿De qué se trata, entonces? Se trataría de reconocer que se ha abierto una nueva fase en la historia de la ética; que no marca ni define precisamente su "renacimiento", sino más bien sólo una diferencia en cuanto a la modalidad con que los valores se inscriben en el contexto social, o la entrada en un ámbito de moralidad donde los valores se encarnan de manera distinta. Por lo tanto, no hay vuelta alguna a etapas anteriores de la cual se pueda dar testimonio en la actualidad. Esta nueva dimensión de la moral, a pesar de que, de hecho, sigue nutriéndose del ideario humanista, en realidad no adhiere a ninguna moral específica anterior. $\mathrm{Ni}$ a las religiosas ni a las laicas, moderno-ilustradas.

La secularización ética que se había venido cumpliendo desde el siglo XVII hasta la primera mitad del nuestro, a pesar de haber buscado emanciparse del espíritu religioso, de todas formas conservó una de sus fi- guras centrales: la de la deuda o el deber absoluto. Así se destacaron la obligación y los deberes, toda una normatividad disciplinaria que conculcó el despliegue individual en nombre de una cierta unidad moral que se consideró necesaria para la cohesión social. Sin embargo, una lógica nueva vino a poner término a esta fase centrada en el deber incondicional. Así, todo indica que, desde mediados del presente siglo, la humanidad ha entrado en una época distinta Lipovetsky la entiende como una época del posdeber (2)—. Ahora son los imperativos del bienestar subjetivo, expresados en modalidades de ética mínima, antes que los de cualquier sacrificio, los que configuran la particular experiencia ética del presente. La sociedad actual no consagra la grandeza moral a una renuncia al sí mismo. Esta nueva ética de la responsabilidad - así la queremos entender hoy en día - se plantea como objetivo poner límites al incremento progresivo de una lógica individualista, mediante la legitimación de nuevas obligaciones colectivas, en particular, aquellas que buscan conciliar el futuro con el presente.

El problema es que, en nuestra época, hacer retroceder al individualismo irresponsable es difícil pues ya no se cuenta con modelo alguno al que se le pueda otorgar total credibilidad. Así, entonces, es como la ética llega a covertirse en un "peligroso remedio clave"; dado que no quedan referentes ideológicos capaces de alentar una salida. De tal modo, el eticismo que caracteriza a las virtuosas proclamas del presente podría constituir a la larga un recurso meramente cosmético, edulcorante, incapaz, en definitiva, de modificar el amargo panorama del presente. ¿Quién asegura que la bioética no es una expresión más de esto mismo?

Cabría, en consecuencia, legítimamente, dudar de la posibilidad de considerar con seriedad a la bioética — que es nuestro verdadero interés- como un paradigma apropiado para enfrentar la presente tensión entre ética y tecnociencia con una radicalidad 
que conduzca, efectivamente, al centro de la cuestión referente a su sentido más pleno, cuando ella inevitablemente se sitúa en el marco de esta suerte de "reduccionismo ético" característico de la actualidad que se presenta al estilo de una especie de panacea insuperable. Lo cierto es que tanto entusiasmo ético como el que puede apreciarse en la actualidad, de ningún modo es sinónimo de verdadera competencia moral para enfrentar los riesgos y abordar los problemas teóricos y prácticos que experimenta la época. Grandilocuentes declaraciones seguidas de acciones estériles sólo podrían llegar a depararnos más frustración y, consecuentemente, un creciente desaliento. No puede ser, por lo mismo, que una simple apología del altruismo y la generosidad, como la que subyace al efecto ético del que hemos venido haciendo mención, constituya el núcleo fundamental del agenciamiento requerido, porque, mientras el discurso eticista se solaza en su retórica neoindividualista, los problemas permanecerán intactos y agobiando cada vez más a las generaciones presentes y futuras.

Ahora bien, tampoco se trata, como casi naturalmente puede entenderse, de la restitución de los imperativos maximalistas o absolutistas del deber, de la ética categórica - menos en un mundo donde la fragmentación de los referentes unitarios y la disolución de los sistemas valorativos son hechos indesmentibles-, porque ello conduciría directamente a tratar de poner en relevancia máxima una especie de "virtuismo" extremo, fóbico con respecto a la ciencia; que, como toda expresión fundamentalista, condenaría prejuiciosa e intransigentemente cualquier forma de desarrollo y experimentación en el ámbito del saber. Ni una ni otra perspectiva pueden dar suficiente legitimidad ni coherencia al discurso bioético en el presente. Así entendidas las cosas, así vislumbrada esta situación aporética, la bioética no resulta ser más que un terreno fértil para la proliferación de la insensatez vacía de cier- tos discursos alarmistas y catastrofistas referidos a una supuesta "deshumanización" actualmente en marcha, y para la convicción analgésica de que un pasado histórico de prácticas paternalistas y abusivas se encuentra completamente superado mediante este discurso supuestamente renovador.

Concluyentemente, entonces, la bioética requiere una comprensión diferente que la que las precedentes aproximaciones pueden tener de ella. Eso es, precisamente, lo que mueve a esta investigación al atrevimiento de sostener que resulta factible - como se intentará explicitar - concebir la bioética en relación con una perspectiva de naturaleza hermenéutica, avanzando en la dirección de situar como eje central de la argumentación respectiva, la noción de interpretación, que se considerará en lo sucesivo desde la perspectiva de su dialogicidad esencial, la que, a su vez, se piensa que posibilita una experiencia moral de diferente filiación y proyección.

Ahora bien, para comprender esta compleja proposición hay que señalar un antecedente decisivo y que tiene que ver con el hecho de que, en oposición al proyecto filosófico prácticamente unánime de la fundamentación, el de la tradición histórica de pensamiento metafísico - condición originaria del cientificismo positivista moderno, digamos-, desde las primeras décadas de nuestro siglo han venido apareciendo planteamientos nuevos, que marcan un verdadero cambio de paradigmas. Están, entre otras, las obras de Heidegger, Gadamer o Ricoeur como ejemplo de la emergencia y la vigencia del pensamiento hermenéutico en cuanto quiebre radical de dicha filosofía metafísica; y decimos radical porque no sólo se han limitado a discutir la validez de las distintas soluciones propuestas anteriormente sino que, de manera frontal, discuten la legitimidad misma del proyecto de búsqueda de un fundamento último, operando, en definitiva, como instancia deconstructiva de la autocomprensión objetivista de las ciencias. 
Un lugar especial en este panorama tiene la obra de Paul Ricoeur, en la medida en que en su paso de la fenomenología a la hermenéutica, más que una simple negativa a la posibilidad de una fundamentación última en la filosofía, se puede advertir una dimensión crítica — con la que cree superar las limitaciones de la propuesta de Heidegger y Gadamer-, articulada en lo que él denomina su "teoría del texto" (3) y que le permitiría establecer una mediación entre la explicación (científica) y la comprensión (hermenéutica). Esta teoría del texto se convierte finalmente para Ricoeur en un modelo general para el estudio de la acción humana en cuanto acción significativa, porque ésta es concebida como una obra abierta, abierta a cualquiera que pueda leer, y por lo mismo, siempre dotada de un significado en suspenso y resistiendo a cualquier pretensión de encapsulamiento unívoco. Justamente, por abrir nuevas referencias, y recibir una nueva pertinencia de ellas, los hechos humanos están siempre esperando nuevas interpretaciones que decidan su significado. "En la misma forma en que un texto se desprende de su autor — además — una acción se desprende de su agente y desarrolla consecuencias que le son propias". Una acción se constituye en un fenómeno social porque nuestros hechos se nos escapan y ejercen efectos que no nos propusimos. Una acción significativa es una acción cuya importancia va más allá de la pertinencia a su situación inicial. Así, se puede llegar a vincular esta comprensión de la acción como texto con la situación particular de una práctica sanitaria que, orientada por una vocación bioética, conciba hermenéuticamente el discurso científico que la fundamenta. Ello podría implicar una diferente comprensión del estatuto ontológico de la salud y la enfermedad.

Pues bien, sustentándonos en lo que acabamos de señalar, hagamos el intento de analogar estas mismas nociones a la situación particular de una práctica sanitaria que mediante una vocación bioética concibe hermenéuticamente el discurso científico que la fundamenta. En ella podría vislumbrarse, probablemente, una disposición más bien diversa a la habitual en relación con la comprensión del estatuto ontológico de la salud y la enfermedad. Según esto, entonces, la presuposición de una estructura de objetividad en la cual el ser de la enfermedad se agota y la enunciación de una multiplicidad visible de síntomas donde ésta adquiere sentido que son recursos habituales sobre los que el saber médico cobra cuerpo- no hacen sino extender un orden particular de verdad en el que se ha desplegado tautológicamente un conjunto técnico y conceptual que se autoasigna un valor fundamental al elaborar sobre el individuo un discurso de estructura científica.

Contrariamente, podríamos anticipar que la mirada hermenéutica es capaz de ver en la enfermedad (o la salud) las condiciones de posibilidad que nos permiten practicar una aproximación a su sentido más esencial, en términos de acción significativa. ¿Qué podría significar esto? Por ahora, digamos simplemente que su comprensión o importancia, por ejemplo, podrían ir más allá de la sola pertinencia a la situación inicial establecida a partir de la puesta en visibilidad del conjunto de síntomas por la que es abordada, involucrando otras circunstancias que explicitaremos luego. O que su propia manifestación abre todo un mundo que está alojado en su esencia y que resiste a ser objeto exclusivo de la cuantificación matemática, abriéndose mejor a la intuición de ciertos remanentes de la significación que duermen en la palabra acotada del lenguaje de la ciencia. Su significado, entonces — como acción significativa-, estará siempre "en suspenso", abriendo nuevas referencias, esperando nuevas interpretaciones que contribuyan al esclarecimiento de su sentido, en estado de apertura a cualquiera que "pueda leer", antes que cerrado en torno al saber específico o a la interpretación privilegiada de una ciencia positiva. 
Según Gadamer (4), la salud producida por el médico como consecuencia de su arte, no constituye propiamente una obra como lo sería la resultante de la producción implicada en la habilidad representada por el sentido de la techne griega. No se trataría de algo nuevo, inexistente hasta la ocasión en que interviene el médico. Se trata, en verdad, de la recuperación o del restablecimiento de algo que existe de antemano: la salud de quien se encuentra enfermo.

Por ello, situada en el contexto de la noción de naturaleza delimitada por las ciencias naturales modernas, la praxis médica se aleja del carácter de arte porque el tipo de saber establecido por tales ciencias no se subordina a lo propiamente natural, sino que, por el contrario, transforma o suplanta a la naturaleza en una construcción humana racional (una "contrarrealidad artificial"). La actividad médica, sentida en estos términos, tiende a consistir en un puro dominio de habilidades, o en la mera construcción planificada de intervenciones exitosas en cuanto su programación racional puede llegar a tornar cada vez más calculadamente dominables los fenómenos. Sin embargo, la medicina puede diferir notablemente de otras ciencias en cuanto al carácter esencial que puede reconocerse en el arte de curar cuando se define en relación con una concepción de la naturaleza como constituida por una inefabilidad esencial irreductible a cualquier cuantificación o problematización artificial.

Parece ser, más bien, que la ciencia y la práctica de este arte de curar que nos ocupa se despliega y transcurre, mucho más que en la proliferación de las técnicas y los saberes específicos, en medio del estrecho corredor que deslinda el ámbito de este conocimiento propio de las ciencias que avanza sobre la naturaleza para dominarla y el inefable misterio de la realidad mental y espiritual de lo humano que enfrenta la enfermedad; es decir, aquel complejo espectro de asuntos inherentes a la experiencia humana, que resultan ser inabordables para las pretensiones de la ciencia y del profesional sanitario que no reconozca que, a pesar del aval de su saber técnico, el único órgano develador de que dispone como lector para acceder a ese "texto" que constituye el paciente — si es que aceptamos la analogía planteada anteriormente- es su propia realidad personal; por lo cual no puede sino admitir que frente a la situación de su contraparte, el enfermo, no existe una interpretación única, mejor que las demás posibles: único es sólo el paciente, cada uno en su total diversidad, la interpretación de sus circunstancias es siempre múltiple. En suma, ya sea que se trate de restablecer la salud que ha dejado de existir, o de cuidar la que ya existe, siempre estará en juego la interpretación abierta de las condiciones, porque ellas, a su vez, siempre pueden ser representadas en nuevos contextos.

De todo esto estamos hablando cuando intentamos homologar la teoría del texto a la comprensión esencial del arte de curar. La clave conceptual "El paciente como texto" enuncia una disposición peculiar del pensar en la que se busca transitar desde el sistema acabado y definitivo del reduccionismo cientificista que toca al ser del hombre como objeto de un saber positivo o exacto, al borde diferencial hermenéutico - basado en el pensar interpretativo - donde lo humano es atestiguado desde su intrínseca condición problemática, inconclusa, conjetural e imprevisible, reticente a cualquier cierre conceptual. Pues, el hecho de que el paciente sea visto como un texto es sinónimo de que en su ser de enfermo pueden emerger palabras que deben ser extraídas del silencio, palabras cuyo decir es siempre múltiple y están a la espera de nuevas interpretaciones que decidan su significación, palabras que, además, estarán abiertas a los muchos que puedan leerlas, a todas las instancias sociales que pueden proveer, en mayor o menor medida, salud.

De esta manera, la intervención médica se ajusta al espacio de reconocimiento de la compleja multidimensionalidad de lo humano, inaprehensible para cualquier esfuerzo 
explicativo que no contemple su vastedad y pluralidad. No hay, en consecuencia, alternativa a la consideración hermenéutica de la instancia médica; el verdadero arte de curar - reiteramos - entiende al paciente en su condición de texto, de realidad abierta y multívoca; así su práctica se enmarca en las delimitaciones de la acción significativa cuya importancia no radica en el apego irrestricto a los marcos rígidos de la situación original que le da forma; es decir a la voluntad reductivista tecnocientífica que pone a lo probable físicamente como lo único relevante- y así escapa a los fantasmas del paternalismo social y la violencia epistemológica. La pérdida de la salud no constituye de ningún modo un acontecimiento aislable dentro de variables únicamente médico-biológicas; es, ante todo, un proceso que se da en medio del tejido históricovital del individuo y su entorno social. Todo esto por una parte.

Por otra, habría que reconocer que existe también otro aspecto importante de la bioética que se puede mencionar. Aquél que busca poner de relevancia un vínculo esencial entre el hombre y la naturaleza, aquél de las preocupaciones medioambientales, ecológicas o "ecosóficas", como las denomina Guattari (5)—. Sobre todo ahora, que el planeta vive un período de intensas mutaciones tecnocientíficas, producto de las cuales se han venido produciendo inestabilidades ecológicas que amenazan a muy corto plazo la vida sobre su superficie.

Porque cada vez resulta más evidente que existe una total incapacidad en las esferas de decisión política y en las instancias ejecutivas de primer nivel mundial para ofrecer otro tipo de soluciones a los problemas del presente que no sean las que emanan de un criterio tecnocrático y economicista. Lo que lleva a suponer que sólo entrecruzamientos éticopolíticos o ético-económicos harían posible una clarificación conveniente para esta delicada situación. Sin duda, ello atraviesa por una radical reorientación tanto de los objeti- vos de la investigación y desarrollo científicos, como de los de la modalidad de producción de los bienes materiales e inmateriales del presente. Resulta, entonces, de crucial importancia visualizar ahora el modo como se vivirá en lo sucesivo en el planeta, en medio de las transformaciones y aceleraciones técnicas que afectan a la sociedad progresivamente y en circunstancias de un crecimiento demográfico que se vislumbra, de todas formas, problemático.

Por tanto, meditar en función de una restitución de la co-pertenencia originaria de hombre y naturaleza, más allá del imperativo tecnocientífico de control y dominación de las fuerzas naturales, es una decisiva tarea del presente. Es preciso enfatizar una concreta vecindad de Hombre y Naturaleza. Ello implica el reconocimiento de que ambos existen en un frente-a-frente, que cada uno concurre inevitablemente a la proximidad del otro, que el hombre "no es esencialmente ajeno al cosmos que lo rodea", como dice Hottois al explicitar su concepto de "solidaridad antropocósmica".

En efecto, nos interesa en este momento dar con las luces que nos orienten hacia una comprensión del entorno vital en sentido hermenéutico y poder formular algo así como ciertas "condiciones de posibilidad" de una ética para tales circunstancias; vale decir, algunas prescripciones fundamentales - aunque no de acción efectiva- que la validen como una propuesta bioética legítima y distinta de la alternativa ecológica propiamente tal, ya que deben reconocerse tanto su origen distinto y su diversidad de intereses como su condición paradigmática de comprensión y acercamiento respecto de los múltiples problemas del presente. Intentaremos, por ello, elaborar una apología del medio ambiente que se sustente en una lectura de la naturaleza como texto, asumiendo para esto la proposición ricoeuriana según la cual "la noción de texto puede ser tomada en un sentido analógico [considerando que] la Edad Media ya pudo hablar de una interpretatio 
naturae, a favor de la metáfora del libro de la naturaleza" (6). Por lo cual, si la noción de texto puede ser ampliada, entonces, también puede serlo la hermenéutica misma, movilizando argumentos semejantes a los que empleamos con anterioridad, ahora, a la intelección de este nuevo objeto del análisis.

Es claro que la "comprensión" técnicocientífica moderna del medio ambiente, su traducción en términos manipulables mediante la disposición de la naturaleza en calidad de "recursos" o stocks, así como el carácter excluyente de su actitud y el antropocentrismo avasallador que se oculta detrás de ella, corresponde en esta analogía textonaturaleza que pretendemos establecer, al desconocimiento más absoluto y radical que se pueda concebir de la emergencia de un sentido nuevo para el sujeto humano. La comprensión tecnocientífica rehúye atender al sentido y el mundo que la naturaleza despliega a partir de sí y clausura, por tanto, la salida hacia el reconocimiento de la propia dependencia humana con respecto a lo otro que el medio ambiente representa. La apercepción del hombre técnico transcurre al margen del reconocimiento de una relación que oscila entre el alejamiento y la proximidad con respecto a su medio natural. Por su carácter esencialmente subjetivo, el mundo natural, el conjunto de los seres vivientes no-humanos, asimismo como los seres inanimados, se le develan en una distancia meramente "objetiva" que le impide comprender comprendiéndose al interior de lo comprendido, no logrando por eso una comprensión radical de ese texto-naturaleza que lo determina y al cual se debe, ni una interpretación de éste que sea, en rigor, una interpretación lúcida de sí mismo.

Ahora, nos parece que se puede pensar que una comprensión concebida en estos términos hermenéuticos puede llegar a propiciar una ética abierta de la experiencia humana, pero no en una apertura que tiende a disolverse en una simple apología de la diversidad irreductible de las opciones morales. Es plausible suponer que la centralidad de la hermenéutica dependa principalmente de su alejamiento del cierre característico del subjetivismo metafísico representado por el cientificismo, $y$, en nuestro caso, por su encarnación en la disposición técnica de la naturaleza. Cierre que se manifiesta en su pretensión de que la experiencia acontezca como reflejo de un sujeto que se quiere transparente.

Una ética hermenéutica, luego, no corresponderá a ninguna descripción "neutral" de objetividades sino más a bien a un evento trans-apropiador en el que las partes (sujetoobjeto, texto-lector, hombre-naturaleza, etc.) se ponen en juego por igual y del cual salen modificadas y en el que se comprenden en cuanto son comprendidas dentro de un horizonte más amplio del que no disponen sino que las dispone. La actitud hermenéutica propicia una ética que trasciende la mera descripción y avanza hacia una particular modalidad de prescripción, que no se inscribe ni en el modelo de prescriptividad universalista de la ética tradicional "univocista" —oclusiva respecto de la alteridad-, ni en la equivocidad absoluta, apologética de la fragmentación que, a su modo, también opera como un cierre para la ética, sino en un tipo de prescriptividad más bien analógica, algo así como "de término medio" y prudencial (7) en cuanto se orienta por el reconocimiento y la consideración del otro que limita y determina el alcance de la prescripción misma. La hermenéutica es diálogo, que debe ejercerse efectivamente más allá de posiciones puramente descriptivistas que soslayen el problema de la relación entre "observador" y "observado".

Como la hermenéutica es diálogo, por tanto, conduce a una configuración dialógica de la ética que apunta al logro de un referente que transite de la dimensión poética a la argumentativa, que se instale como un tercero, como un medium que alienta la posibilidad de comprensión y relación con el otro, de identificación simpatética con la alteridad, que avale, en definitiva, la consolidación de una humanidad no más "sujeta". 
En una bioética hermenéutica, la fundamentación de una instancia prescriptiva en los términos que se ha señalado anteriormente, capaz de constituirse en una orientación razonable y prudencial para el proceso deliberativo y la acción referida a la crisis medioambiental del presente, se debe apreciar como una cuestión posible de acometer y sostener, si y sólo si, en una concepción de realidad en la que estén incluidos como interlocutores válidos o potenciales del hombre todos los posibles participantes de un diálogo moral en el que se ha dislocado la centralidad de lo humano, y aunque ello no ha quedado exactamente remitido a una periferia insignificante, tampoco permanece en el lugar de "señorío" en el que la tradición lo ha puesto desde el relato bíblico del Génesis hasta nuestros días, porque hay en el presente una evidente fractura de la racionalidad subjetivista, porque hay una insostenibilidad del paradigma del sujeto moderno y la razón monológica que lo impide. El fenómeno de la crisis del humanismo que fuera detectado en nuestra época así lo indica y, al menos en algún sentido, implica esta pérdida de rango, esta diseminación de la jerarquía antropocentrista; la misma que se puede considerar responsable de las contingencias desesperanzadoras y riesgosas que se ciernen sobre el presente y la cotidianeidad, que se han trasuntado en la vigencia del individualismo irresponsable imperante y violentador, directamente e indirectamente, del planeta aquí y ahora.

Una bioética hermenéutica, entonces, no concebirá su tarea como un asunto de prescripción normativa para la administración más racional y depurada de los "recursos", por ejemplo, porque ello dejaría todo donde mismo; ya que el sustrato de racionalidad tecnocientífica permanece intacto en una concepción de este tipo, pues así no deja de seguir siendo instrumental y antropocéntrica y, por tanto, incapaz de impedir que el hombre continúe "pavoneándose" como Señor de la tierra. Por el contrario, el reajuste jerár- quico del sujeto implicado en el cambio que lo conduce de su concepción en cuanto lector privilegiado o intérprete excluyente de la supuesta objetividad del "texto" natural, a la concepción hermenéutica de sujeto dispuesto a dejarse apropiar por el "mundo" del texto - al margen de explicaciones objetivas y localizaciones de superioridad-, muestra que una ética medioambiental debe ser, más que una contabilidad de datos y proyecciones cuantitativas de "explotabilidad" posible para no "agotar" las subsistencias, la comprensión de esa íntima y polifónica relación de transferencia existencial que entrecruza los diversos sentidos y las múltiples sensibilidades de lo vivo que no son admitidas en el enunciado científico-técnico. Porque la determinación de los focos de vida parciales, de aquello que puede dar consistencia enunciativa o soporte de reconocimiento en calidad de existente a la multiplicidad de lo viviente, no depende exclusivamente de una pura descripción objetiva sino de una suerte de narración cuya primera función no es engendrar una explicación racional sino una convergencia de acontecimientos; porque, además, debe entenderse que tras la diversidad de los entes no está dado ningún zócalo ontológico sino un plano reticulado de interfaces múltiples.

Al mismo tiempo, en una bioética hermenéutica la actitud adecuada en función del entorno no puede ser vista ni como un retiro ni como una renuncia a salirle al encuentro en una relación de cercanía. Porque éste no es percibido en el sentido de un "todo indiferenciado", al estilo de una unidad mística ante la cual sólo es válida la pretensión de la autorealización en el sentido específico en que la ha entendido la ecología profunda; es decir, como un holismo que termina siendo excesivo en la medida que no reconoce que las entidades naturales no son exactamente lo mismo y no pueden ser consideradas, tampoco, exactamente de igual manera. Una muestra de ello puede encontrarse fácilmente si, por ejemplo, pensamos en que a pesar del hecho 
reconocido por la medicina de que somos simbióticamente habitados por organismos residentes microscópicos — vale decir, como si fuéramos una sola vida-, cada organismo reconoce inconscientemente la diferencia fundamental entre sí mismo y el otro y responde inmunológicamente cuando su identidad como individuo ha sido violada. Por ello, una prescripción medioambiental hermenéutica instará al reconocimiento de la individualidad en la medida que ella se entienda en mutua solidaridad con otras formas vivientes a las que se vincula y de las que también depende y que redefinen su propio estatuto vital a través de ese particular vínculo.

Por otra parte, tampoco a una bioética hermenéutica se le puede concebir como aval de una acción emancipante respecto de la supuesta e idéntica desmedrada situación genérica de la mujer y la naturaleza que el ecofeminismo quiere enarbolar como estrategia político-conceptual, porque más bien la existencia virtual de dicha situación queda incluida como elemento de una condición marginalizante, irrespetuosa y avasalladora generalizada que acontece, incluso, intergenéricamente al interior de la misma realidad masculina, que no se desea bajo ninguna expresión, y que la aproximación hermenéutica (de la analogía texto-naturaleza) permite dejar atrás. Asimismo, su tarea se aleja de toda consideración ética que haga tabula rasa de la diversidad y la diferencia gradual de la sensibilidad que otorga un criterio de base para ponderar sensatamente el estatuto moral que pudiera tener cada individuo viviente.
Todos estos deslindes teóricos que ponen a nuestra propuesta más allá (aunque no en total oposición) de las éticas medioambientales descritas con anterioridad, hacen que el modelo hermenéutico de la comprensión enmarque el desarrollo de una bioética referida a la acción humana desplegada en el mundo circundante, dentro de las exigencias formales planteadas, que, creemos, contribuyen a darle la solidez y legitimidad que requiere para sostener su pretensión paradigmática y su aspiración de ser expresión valedera de comprensión de los problemas de nuestro tiempo y clave de aproximación y distanciamiento hacia lo inefable, hacia lo irreductible de la naturaleza que nos alberga.

\section{Referencias}

1. Hottois G. El paradigma bioético. Barcelona: Anthropos; 1991.

2. Lipovetsky G. El crepúsculo del deber. Barcelona: Anagrama; 1996.

3. Ricoeur P. Hermenéutica y acción: de la hermenéutica del texto a la teoría de la acción. Buenos Aires: Docencia; 1995.

4. Gadamer HG. El estado oculto de la salud. Barcelona: Gedisa; 1996.

5. Guattari F. Las tres ecologías. Valencia. En prensa 1990.

6. Beuchot M. Tratado de hermenéutica analógica. México: UNAM; 1997.

7. Vattimo G. Ética de la interpretación. Barcelona: Paidós; 1991: 59-62 